\title{
Article
}

\section{A 3D Lead Iodide Hybrid Based on a 2D Perovskite Subnetwork}

\author{
Maroua Ben Haj Salah ${ }^{1}$, Justine Tessier ${ }^{1}$, Nicolas Mercier ${ }^{1, *}{ }^{\circledR}$, Magali Allain ${ }^{1}{ }^{(\mathbb{C}}$, Antonin Leblanc ${ }^{1}$, \\ Xiaoyang Che ${ }^{2}$, Claudine Katan ${ }^{2}$ (D) and Mikael Kepenekian ${ }^{2, *(D)}$ \\ 1 MOLTECH-Anjou, UMR-CNRS 6200, Université d'Angers, 2 Bd Lavoisier, 49045 Angers, France; \\ maroua.benhajsalah@univ-angers.fr (M.B.H.S.); justine72.tessier@gmail.com (J.T.); \\ magali.allain@univ-angers.fr (M.A.); antonin.leblanc49@gmail.com (A.L.) \\ 2 Univ Rennes, ENSCR, INSA Rennes, CNRS, ISCR (Institut des Sciences Chimiques de Rennes), UMR 6226, \\ F-35000 Rennes, France; xiaoyang.che@gmail.com (X.C.); claudine.katan@univ-rennes1.fr (C.K.) \\ * Correspondence: nicolas.mercier@univ-angers.fr (N.M.); mikael.kepenekian@univ-rennes1.fr (M.K.)
}

check for updates

Citation: Ben Haj Salah, M.; Tessier, J.; Mercier, N.; Allain, M.; Leblanc, A.; Che, X.; Katan, C.; Kepenekian, M. A 3D Lead Iodide Hybrid Based on a 2D Perovskite Subnetwork. Crystals 2021, 11, 1570. https://doi.org/ $10.3390 /$ cryst 11121570

Academic Editor: Dmitry Medvedev

Received: 1 December 2021

Accepted: 14 December 2021

Published: 16 December 2021

Publisher's Note: MDPI stays neutral with regard to jurisdictional claims in published maps and institutional affiliations.

Copyright: (c) 2021 by the authors. Licensee MDPI, Basel, Switzerland. This article is an open access article distributed under the terms and conditions of the Creative Commons Attribution (CC BY) license (https:// creativecommons.org/licenses/by/ $4.0 /)$.

\begin{abstract}
Lead halide perovskites have emerged as promising materials for various optoelectronic applications. For photovoltaics, the reference compound is the $3 \mathrm{D}$ perovskite $(\mathrm{MA}) \mathrm{PbI}_{3}\left(\mathrm{MA}^{+}=\right.$methylammonium). However, this material suffers from instabilities towards humidity or light. This makes the search of new stable 3D lead halide materials very relevant. A strategy is the use of intermediate size cations instead of $\mathrm{MA}$, which are not suitable to form the $3 \mathrm{D} \mathrm{ABX}_{3}$ perovskites or 2D perovskites. Here, we report on a novel 3D metal halide hybrid material based on the intermediate size cation hydroxypropylammonium $\left(\mathrm{HPA}^{+}\right),(\mathrm{HPA})_{6}(\mathrm{MA}) \mathrm{Pb}_{5} \mathrm{I}_{17}$. We will see that extending the carbon chain length from two $\mathrm{CH}_{2}$ units (in the hydroxylethylammonium cation, $\mathrm{HEA}+$ ) to three $\left(\mathrm{HPA}^{+}\right)$precludes the formation of a perovskite network as found in the lead and iodide deficient perovskite (HEA,MA) $)_{1+x} \mathrm{~Pb}_{\mathrm{x}} \mathrm{I}_{3-\mathrm{x}}$. In (HPA) 6 (MA) $\mathrm{Pb}_{5} \mathrm{I}_{17}$ the 3D lead halide network results from a 2D perovskite subnetworks linked by a $\mathrm{PbI}_{6}$ octahedra sharing its faces. DFT calculations confirm the direct band gap and reveal the peculiar band structure of this 3D network. On one hand the valence band has a $1 \mathrm{D}$ nature involving the $\mathrm{p}$ orbitals of the halide. On the other, the conduction band possesses a clear 2D character involving hybridization between the $\mathrm{p}$ orbitals of the metal and the halide.
\end{abstract}

Keywords: 3D network; halide perovskite; electronic structure; lead iodide hybrid

\section{Introduction}

Halide perovskites became superstar semiconductors in recent years, especially for photovoltaic applications [1-4]. The reference compound is $(\mathrm{MA}) \mathrm{PbI}_{3}\left(\mathrm{MA}^{+}=\right.$methylammonium) which adopts an $\mathrm{ABX}_{3}$ perovskite structure. This structure can be described by corner-sharing $\mathrm{BX}_{6}$ octahedra which extend along the three directions of space (3D perovskite), the $\mathrm{A}^{+}$cation being located in the middle of space defined by eight adjacent corner-sharing octahedra. The electronic structure has also a 3D character, meaning that charge transport can occur effectively in the whole space which is key for an efficient photovoltaic effect [1]. However, (MA) $\mathrm{PbI}_{3}$ suffers from instabilities towards humidity or light, mainly due to the volatile $\mathrm{MA}^{+}$cation [5]. Different strategies have been considered to improve the stability of such materials. One is to partially or completely substitute $\mathrm{MA}^{+}$ by other cations. This has led to the multiple cation family $\left(\mathrm{A}, \mathrm{A}^{\prime}, \mathrm{A}^{\prime \prime}\right) \mathrm{PbI}_{3}$, the A site of the perovskite being occupied by three types of cations such as $\mathrm{Cs}^{+}, \mathrm{Rb}^{+}, \mathrm{MA}^{+}, \mathrm{FA}^{+}[6-8]$. Another strategy is the use of layered perovskites instead of the 3D perovskite as active material [9-11]. The general formula of the most familiar family is $\left(\mathrm{RNH}_{3}\right)_{2}(\mathrm{~A})_{\mathrm{n}-1} \mathrm{~Pb}_{\mathrm{n}} \mathrm{X}_{3 \mathrm{n}+1}$, also known as Ruddlesden-Popper (RP) phases [12,13]. In such structures, long-size organic cations $\mathrm{RNH}_{3}{ }^{+}$separate layers $(\mathrm{n}=1)$ or multilayers $(\mathrm{n}>1)$ of perovskite type $\left(\mathrm{PbX}_{6}\right.$ corner-sharing mode). These materials appear much more stable than their 3D congeners due to the hydrophobic effect of $\mathrm{RNH}_{3}{ }^{+}$cations [9]. However, while in photovoltaic devices, the charge transport takes place along the direction perpendicular to the substrate, 
these layered compounds naturally grow with perovskite layers parallel to the substrate which is therefore very unfavorable for efficient solar cells. Noteworthy, a hot-casting technique has been shown to favor the growth of perovskite layers perpendicular to the substrate [14], but this hinders further upscaling and large area thin film fabrication.

In this context, the quest for original 3D metal halide materials is of great interest. If a few small-size cations can form the 3D perovskite network, and large-size organic cation afford 2D layered structures, the case of intermediate size cations remains almost unexplored. Too large to form $3 \mathrm{D} \mathrm{ABX}_{3}$ perovskites and too small to form $2 \mathrm{D}$ perovskites, they can lead to unique structure types [15-20]. Thus, the hydroxyethylammonium $\left(\mathrm{HEA}^{+}\right)$ cation leads to maintain a corner-sharing $3 \mathrm{D}$ connectivity in which some $(\mathrm{PbI})^{+}$units are replaced by $\mathrm{HEA}^{+}$in materials called $d$-HP (lead and iodide deficient-perovskites), (HEA, $\mathrm{MA})_{1+\mathrm{x}} \mathrm{Pb}_{\mathrm{x}} \mathrm{I}_{3-\mathrm{x}}$ ) which appear more stable than the reference compounds (MA) $\mathrm{PbI}_{3}$ or $(\mathrm{Cs}, \mathrm{FA}) \mathrm{PbI}_{3}[15,16]$. Dications such as ethylendiammonium or propylenediammonium also afford such compounds called hollow perovskites (disordered structures) $[17,18]$. In most cases, such intermediate size cations lead to 2D (or 1D) networks exhibiting two kinds of connectivity among edge-, face-, and corner-sharing [19,20], which consequently are not perovskite networks [21]. 3D metal halide networks are rarer. In the tin iodide system, a series of $\mathrm{ASnI}_{3}\left(\mathrm{~A}^{+}=\right.$guanidinium, ethylammonium) compounds has been found, the $3 \mathrm{D}$ iodostannate network being based on corner- and face-sharing octahedra [22]. More recently, a series of pyrazinium-based dications $\left(\mathrm{A}^{\prime 2+}\right)$ has afforded the $\left(\mathrm{A}^{\prime \prime}\right) \mathrm{Pb}_{2} \mathrm{X}_{6}$ compounds whose structures are based on $3 \mathrm{D}$ networks of corner- and edge-sharing lead halide octahedra [23].

Here we report on a new metal halide material that has a 3D network of interconnected $\mathrm{PbI}_{6}$ octahedra, using the hydroxypropylammonium $\left(\mathrm{HPA}^{+}\right)$cation, $(\mathrm{HPA})_{6}(\mathrm{MA}) \mathrm{Pb}_{5} \mathrm{I}_{17}$. It is demonstrated that extending the carbon chain length from two $\mathrm{CH}_{2}$ units $\left(\mathrm{HEA}^{+}\right.$) to three $\left(\mathrm{HPA}^{+}\right)$precludes the formation of a perovskite network as found in HEA-based $d$-HP $[15,16]$. In (HPA $)_{6}(\mathrm{MA}) \mathrm{Pb}_{5} \mathrm{I}_{17}$ the 3D lead halide framework results from 2D perovskite subnetworks linked by $\mathrm{PbI}_{6}$ face-sharing octahedra. The properties of the newly synthetized material are further investigated based on DFT electronic structure calculations and optical absorption measurements revealing a direct band gap and reduced electronic dimensionality.

\section{Materials and Methods}

$\mathrm{PbI}_{2}$ (99\%), methylamine solution $40 \%$ in water, 3-amino-1-propanol, hydroiodic acid $57 \%$ in water, were purchased from commercial sources (Sigma-Aldrich) and were used as received without any purification. The organic salts 3-aminium-1-propanol iodide (HPA, I) and methylammonium iodide (MA, I) were first prepared from HI solution containing organic molecules. The iodoplumbate salt $(\mathrm{HPA})_{6}(\mathrm{MA}) \mathrm{Pb}_{5} \mathrm{I}_{17}$ was then prepared by a liquid-gas slow diffusion technique. Details of syntheses are given in the supplementary materials. The purity of the obtained compound was checked by both PXRD (D8 diffractometer from Bruker (Karlsruhe, Germany), Supplementary Materials, Figure S1, all experimental lines well fit with calculated ones from single-crystal X-ray data) and ${ }^{1} \mathrm{H}$ NMR (Bruker ultrashieldTM 300 (Germany), Figure S2, the expected HPA/MA ratio of 6 is found).

X-ray single-crystal diffraction data of $(\mathrm{HPA})_{6}(\mathrm{MA}) \mathrm{Pb}_{5} \mathrm{I}_{17}$ were collected at $149 \mathrm{~K}$ on a Rigaku Oxford Diffraction (Rigaku Europe, Neu-Isenburg, Germany) SuperNova diffractometer. The structure was solved by direct methods, expanded and refined on $\mathrm{F}^{2}$ by full matrix least-squares techniques using SHELX programs (SHELXS 2013/1 and SHELXL 2013/4), leading to R1 factor of 0.0387. A summary of crystallographic data and refinement results for this structure is given in the Supplementary Materials (Table S1). CCDC-2122380.

First-principles calculations are based on density functional theory (DFT) as implemented in the SIESTA package (v5.0.0-alpha) [24,25]. The nonlocal van der Waals density functional of Dion et al. corrected by Cooper (C09) $[26,27]$ was used for full geometry opti- 
mizations, i.e., of atomic positions and cell vectors, while the centrosymmetry is preserved. The electronic structure of the relaxed geometry is described including spin-orbit coupling through the on-site approximation as proposed by Fernández-Seivane et al. [28]. To prevent conflicts between the on-site treatment and the nonlocality of $\mathrm{C} 09$, single point calculations were conducted with the revPBE functional on which C09 is based [29]. Core electrons are described with Troullier-Martins pseudopotentials [30], while valence wavefunctions are developed over double- $\zeta$ polarized basis set of finite-range numerical pseudoatomic orbitals [31]. In all cases, an energy cutoff of 150 Ry for real-space mesh size was used. Electronic structures were converged using k-point samplings of the Brillouin zone of $5 \times 3 \times 3$.

\section{Results}

\subsection{Crystal Structure, Thermal Stability, and Optical Properties}

A slow diffusion of ethanol into an acidic solution (HI) containing hydroxypropylamine, methylamine, and lead iodide (see Section 2) affords needle like crystals of $(\mathrm{HPA})_{6}(\mathrm{MA}) \mathrm{Pb}_{5} \mathrm{I}_{17}$. Figure 1 shows a general view of the structure. The compound crystallizes in the triclinic $P-1$ space group, the independent space containing $3 \mathrm{HPA}^{+}$ molecules, half $\mathrm{MA}^{+}, 2 \mathrm{~Pb}^{2+}$ and $8 \mathrm{I}^{-}$in general positions, and $1 \mathrm{~Pb}^{2+}$ and $1 \mathrm{I}^{-}$located on symmetry centers. The metal iodide network consisting of connected $\mathrm{PbI}_{6}$ octahedra has a 3D character. It can be described from a 2D perovskite subnetwork (purple octahedra, Figure 1) connected to each other by $\mathrm{PbI}_{6}$ face-sharing octahedra (grey octahedra, Figure 1). The 2D perovskite subnetwork of corner-sharing octahedra is isolated on Figure $2 \mathrm{a}$, the different views, along $a, b$, and $c$, highlighting the corner-sharing octahedra mode. The $2 \times$ 2 octahedra building unit centered in the middle of the unit cell (when viewed along the $a$ direction, Figures 1 and $2 \mathrm{a}$ ) can be considered as a part of the $\mathrm{n}=2$ layered perovskite $\mathrm{Pb}_{2} \mathrm{I}_{7}$. The repetition of these units along $a$ leads to a $1 \mathrm{D}$ subnetwork $\mathrm{Pb}_{4} \mathrm{I}_{18}$. A similar situation is found in the structure of $(\mathrm{PA})_{5} \mathrm{~Pb}_{5} \mathrm{I}_{18}\left(\mathrm{PA}^{+}\right.$: propylammonium) compound [19]. However, while these $1 \mathrm{D}$ chains are connected through $\mathrm{PbI}_{6}$ face-sharing octahedra in ( $\mathrm{PA})_{5} \mathrm{~Pb}_{5} \mathrm{I}_{18}$ leading to an overall 2D lead iodide network in this structure, these $1 \mathrm{D}$ chains are connected to each other through corner-sharing mode leading to a $2 \mathrm{D}$ step-like $\mathrm{Pb}_{4} \mathrm{I}_{17}$ $\left(\mathrm{Pb}_{4} \mathrm{I}_{16} \mathrm{I}_{2 / 2}\right.$, two shared iodides) perovskite network extending along the $a$ and $b$ directions of the unit cell. As already mentioned, these $2 \mathrm{D}$ perovskite subnetworks are linked by $\mathrm{Pb}^{2+}$ cations located on symmetry centers, with corresponding octahedra sharing faces with their two neighboring octahedra, leading finally to the overall $3 \mathrm{D} \mathrm{Pb}_{5} \mathrm{I}_{17}$ network.

While $\mathrm{MA}^{+}$cations are located near the shared iodides connecting adjacent $2 \times 2$ octahedra units within the 2D perovskite subnetwork, the $\mathrm{HPA}^{+}$are clearly located in channels defined by this open framework. Figure $2 b$ shows a partial view of the structure focusing on one channel whose section is defined by 10 adjacent lead iodide octahedra, containing $6 \mathrm{HPA}^{+}$cations. We observe 3 kinds of $\mathrm{HPA}^{+}$cations. They are numbered 1 , 2 , and 3 on Figure $2 b$. HPA(1) and $\operatorname{HPA}(3)$ at the surface of cavities clearly interact with iodides through both $\mathrm{NH}$... .I and $\mathrm{OH}$... .I interactions (see Figure 2b, such interactions with H ... I distances $<3.05 \AA$ are drawn as dashed lines). In contrast, HPA(2) cations located at the center of channels do not interact with iodides through sizeable hydrogen bonding (<3.05 $\AA$ ). Meanwhile, two adjacent HPA(2) molecules mainly interact together through strong $\mathrm{NH} \ldots$. . O interactions $(\mathrm{d}(\mathrm{H} \ldots \mathrm{O})=2 \AA)$. The peculiar curled conformation of $\mathrm{HPA}^{+}$, related to the hydrogen bond ability of both the $\mathrm{NH}_{3}{ }^{+}$and the $\mathrm{OH}$ ends, certainly hinders formation of 2D perovskites, while favoring here a structure having a 3D metal halide network, as already observed for other intermediate size cations [23]. 


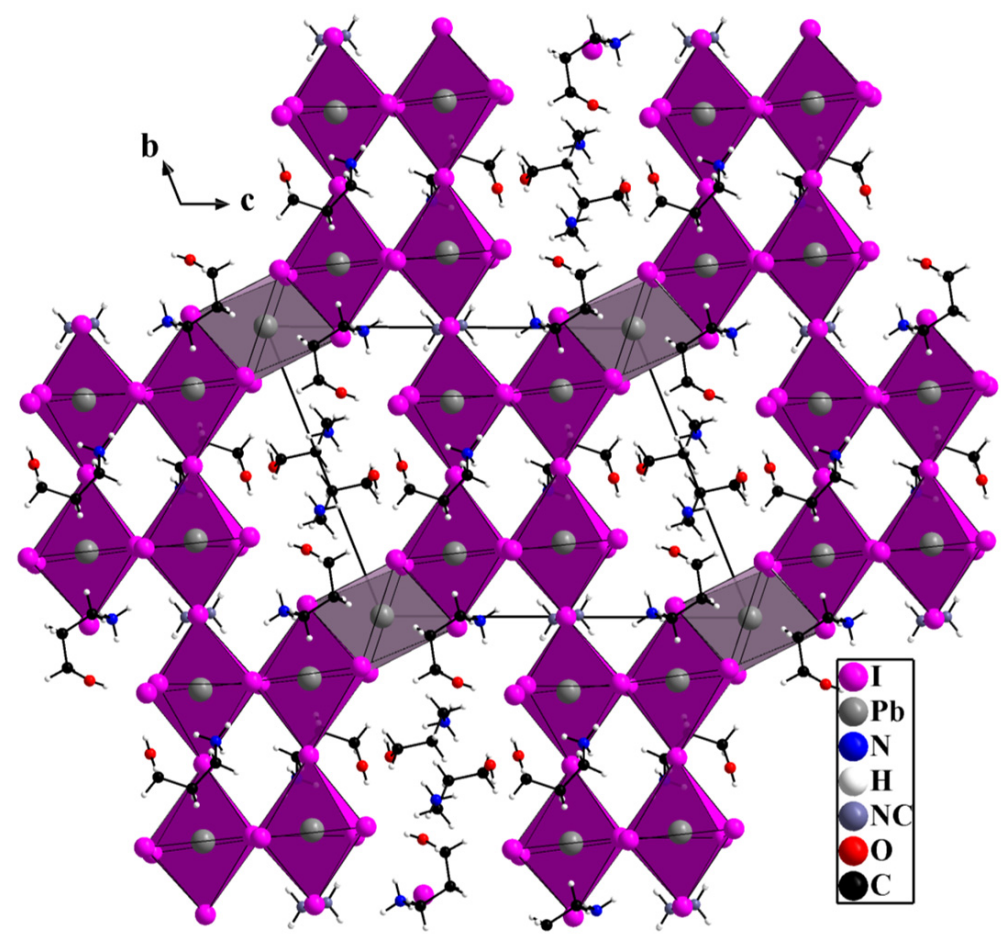

Figure 1. General view of the structure of $(\mathrm{HPA})_{6}(\mathrm{MA}) \mathrm{Pb}_{5} \mathrm{I}_{17}$ showing the $3 \mathrm{D}$ lead iodide network resulting from $2 \mathrm{D}$ perovskite subnetwork (purple octahedra) linked together by $\mathrm{PbI}_{6}$ face-sharing octahedra (grey octahedra).

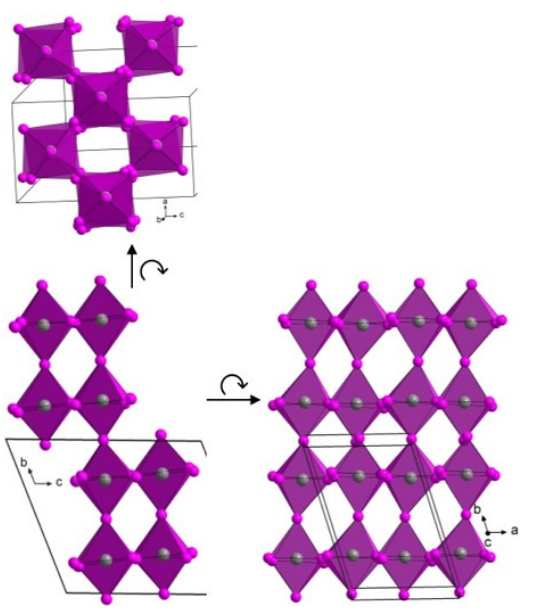

(a)

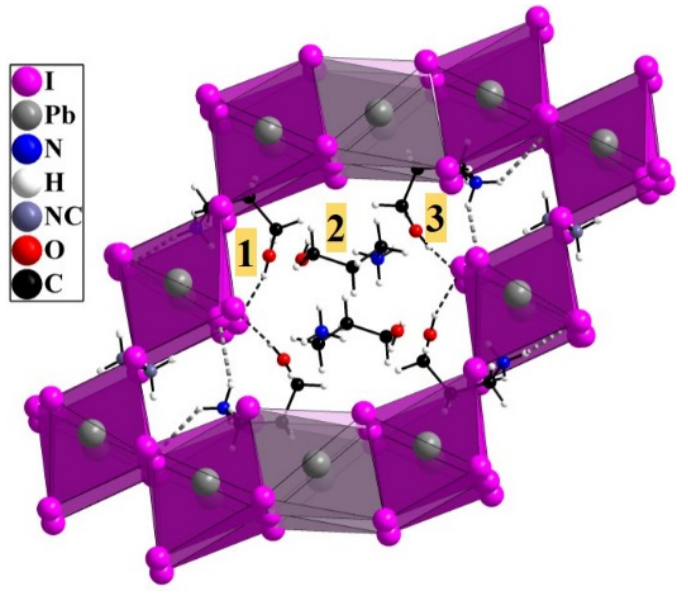

(b)

Figure 2. Structure of $(\mathrm{HPA})_{6}(\mathrm{MA}) \mathrm{Pb}_{5} \mathrm{I}_{17}$. (a) Partial view showing the $2 \mathrm{D}$ perovskite subnetwork along $a, b$, and $c$ highlighting the corner-sharing connectivity; (b) partial view showing organic cations $\mathrm{HPA}^{+}$and $\mathrm{MA}^{+}$in channels defined by corner- and face-sharing $\mathrm{PbI}_{6}$ octahedra, highlighting the three types of $\mathrm{HPA}^{+}$cations (numbered 1, 2, and 3) and hydrogen bonding $(\mathrm{OH} \ldots$.I and $\mathrm{NH}$ ... .I contacts $<3.05 \AA$, dashed lines).

We further explored the stability of (HPA $)_{6}(\mathrm{MA}) \mathrm{Pb}_{5} \mathrm{I}_{17}$ upon heating. TGA experiment shows that the compound is stable up to $200{ }^{\circ} \mathrm{C}$ and decomposes into two steps (Figure S3). Its stability in ambient air appears improved as compared to the well-known $3 \mathrm{D} \mathrm{MAPbI}_{3}$, since PXRD of a sample left in the air during two weeks is similar to the pristine one (Figure S4). Optical properties were investigated on $(\mathrm{HPA})_{6}(\mathrm{MA}) \mathrm{Pb}_{5} \mathrm{I}_{17}$ obtained as a crystallized powder. The absorption spectrum shown in Figure 3a reveals a broad absorption band in the first part of the visible region (400-550 $\mathrm{nm}$ range). The corresponding Tauc plot 
(Figure $3 \mathrm{~b}$ ) leads to a direct optical band gap of $2.33 \mathrm{eV}$. The (HPA) ${ }_{6}(\mathrm{MA}) \mathrm{Pb}_{5} \mathrm{I}_{17}$ crystallized powder also exhibits a weak broad band photoluminescence emission centered at $530 \mathrm{~nm}$ (Figure S5).
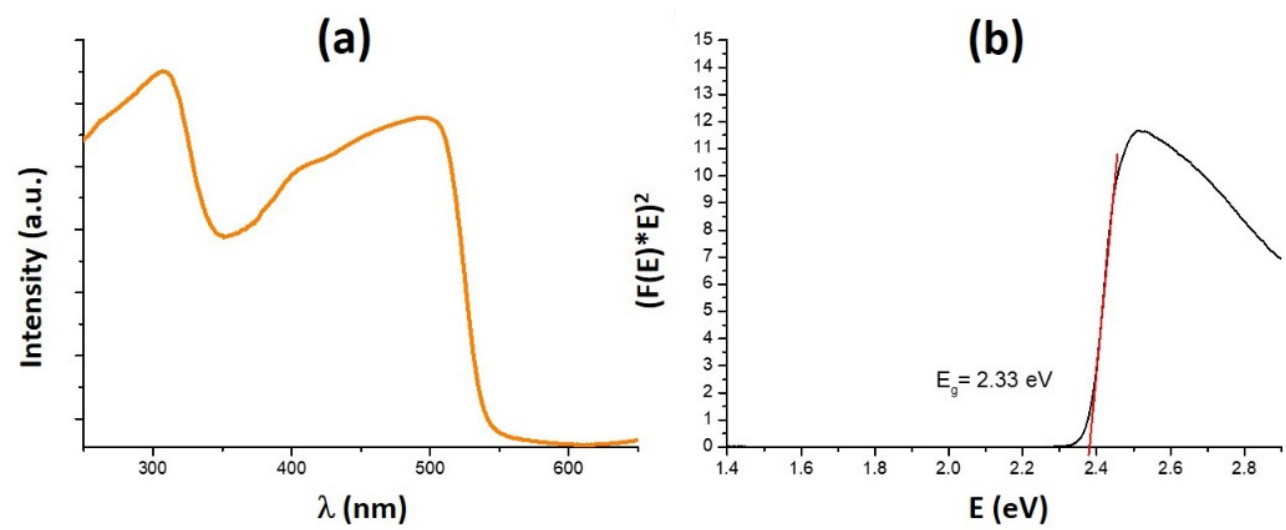

Figure 3. Absorption spectrum of a crystallized powder of (HPA) 6 (MA) $\mathrm{Pb}_{5} \mathrm{I}_{17}$ (a) and corresponding Tauc plot (black curve) assuming a direct band gap ((b), red line: fitted line giving Eg).

\subsection{Electronic Structure}

Insights into the electronic structure of $(\mathrm{HPA})_{6}(\mathrm{MA}) \mathrm{Pb}_{5} \mathrm{I}_{17}$ is provided by first-principles calculations based on density functional theory (DFT). Figure 4a shows the band structure computed at the GGA level (see Section 2 for computational details) that provides reliable description of the electronic features despite the well-known band gap underestimation. The band structure presents a direct band gap of $1.60 \mathrm{eV}$ at $\mathrm{T}$. We verify that the valence band maximum (VBM) is governed by I $(5 p)$ orbitals, while the conduction band minimum $(\mathrm{CBM})$ is due to $\mathrm{Pb}(6 p)$ and $\mathrm{I}(5 p)$ orbitals (Figure S7), i.e., no cation, HPA or MA, state is found near the band edges. Interestingly, the band structure does not adopt the typical shape found for 3D, 2D, nor 1D halide perovskites. Indeed, the lower energy conduction band is flat in one direction, along $c$, and strong dispersion is observed along the two others. Such features are typically found in 2D perovskites, where flat bands correspond to the stacking direction. On the other hand, the top valence band presents sizeable dispersion only along $a$, a characteristic expected for 1D systems.

The negligible dispersion along $c$, observed both in the conduction and valence band can be assigned to the presence of the $2 \mathrm{D}$ perovskite subnetwork (vide supra) separated by the large cation (HPA) and the face-sharing octahedra that efficiently block the electronic coupling between layers as it has been described in previous cases [19,32]. The partial charge density plotted at the CBM (Figure $4 \mathrm{~b}$ ) adopts the form typically observed in layered perovskites with a large contribution from $\mathrm{Pb}(6 p)$ and $\mathrm{I}(5 p)$ orbitals along $a$ and $b$, i.e., the two directions with corner-sharing octahedra. It leads to the important bandwidth following the line Z-T-R (Figure 4a). The case is different with partial charge density taken at the VBM (Figure 4c,d) that illustrates the strong interaction between iodide atoms along $a$ responsible for the dispersion observed along the T-R line. As opposed to the typical shape of valence band in halide perovskites, almost no contribution arises from $\mathrm{Pb}(6 s)$ orbitals. Instead, I $\left(5 p_{x}\right)$ orbitals directly overlap thanks to the zigzag connectivity of the octahedra in the $(a, c)$ plane. The direct overlap between I $(5 p)$ orbitals along $a$ leads to greater interaction and therefore to a higher energy of this anti-bonding combination. Since, the coupling in the $b$ direction is of the classical $\mathrm{I}(5 p)-\mathrm{Pb}(6 s)-\mathrm{I}(5 p)$ form, it lies lower in energy. As a result, the VBM is formed by couplings only along the $a$ direction, giving a 1D-like character to the valence states. 

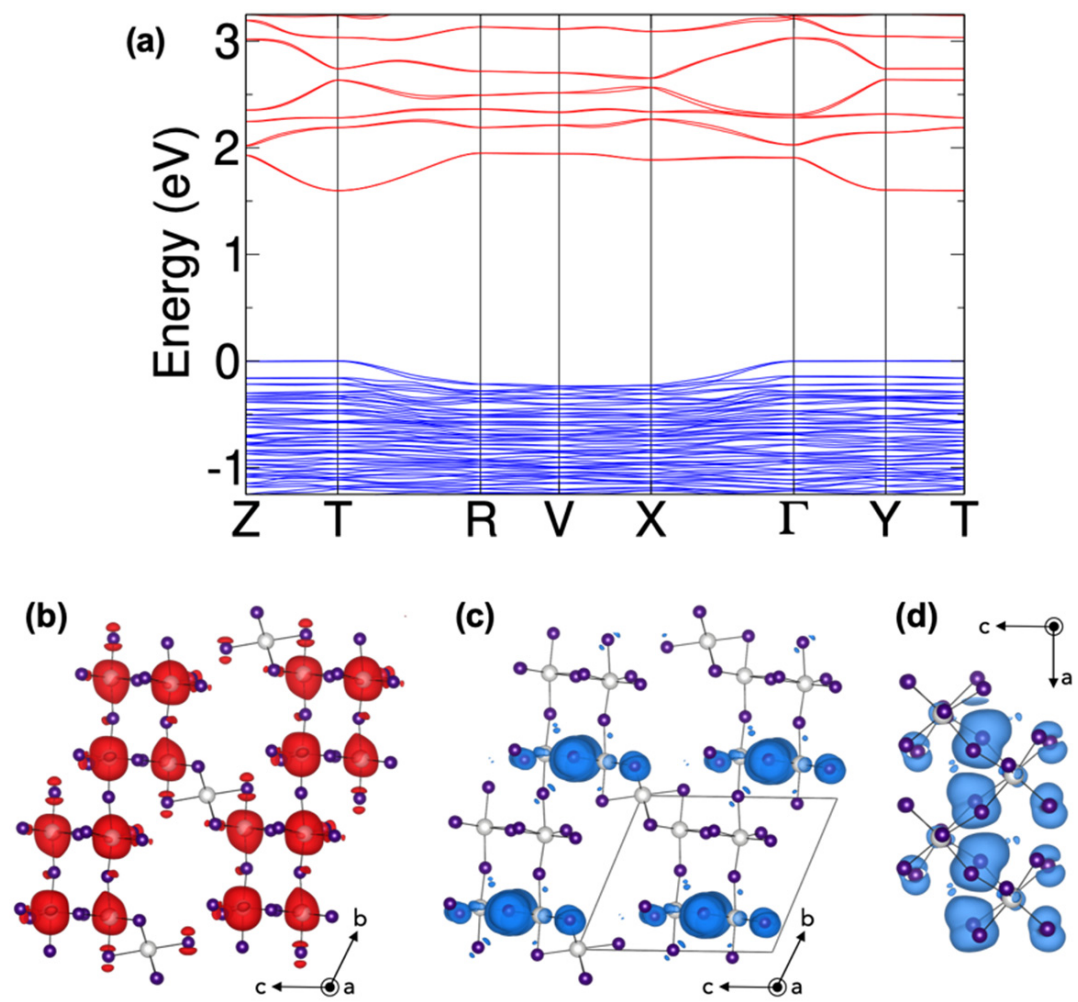

Figure 4. (a) Computed band structure (blues lines: valence band, red lines: conduction band) of $(\mathrm{HPA})_{6}(\mathrm{MA}) \mathrm{Pb}_{5} \mathrm{I}_{17}$. The system presents a direct band gap at $\mathrm{T}$ with $\mathrm{E}_{\mathrm{G}}=1.60 \mathrm{eV}$. $(\mathbf{b}, \mathbf{c})$ Partial charge densities computed at the conduction band minimum and the valence band maximum, respectively. (d) Same as (c) from a different viewpoint. Organic cations are not depicted for clarity (purple atoms: I, white atoms: $\mathrm{Pb}$ ).

Even though not quantitative, it is worth noticing that the here-computed bandgap $(1.60 \mathrm{eV})$ is greater than the ones computed at the same level of theory not only for 3D halide perovskites, but also for typical 2D ones (1.1-1.3 eV). Still, it remains smaller than bandgaps of related 1D-like compounds $(2.0 \mathrm{eV})$ [33]. This is indicative that the electronic dimensionality of the $3 \mathrm{D}(\mathrm{HPA})_{6}(\mathrm{MA}) \mathrm{Pb}_{5} \mathrm{I}_{17}$ structure is intermediate between $1 \mathrm{D}$ and $2 \mathrm{D}$.

\section{Conclusions}

Using the hydroxypropylammonium $\left(\mathrm{HPA}^{+}\right)$intermediate size cation, a new metal halide organic-inorganic material was synthesized. The X-ray structure determination reveals a rare and unprecedented $3 \mathrm{D}$ inorganic network. The structure consists of a $2 \mathrm{D}$ perovskite subnetwork of corner-sharing $\mathrm{PbI}_{6}$ octahedra that are in turn connected to each other by $\mathrm{PbI}_{6}$ octahedra sharing their faces. This compound absorbs in the $400-550 \mathrm{~nm}$ visible range leading to an optical band gap of $2.33 \mathrm{eV}$. DFT calculations further reveal that this 3D structural network has a peculiar band structure that shows a direct band gap but reduced electronic dimensionality. On one hand, the valence band has a 1D nature and is mainly composed of $\mathrm{p}$ orbitals of the halide. On the other hand, the conduction band possesses a clear $2 \mathrm{D}$ character with contributions of $\mathrm{p}$ orbitals of both the metal and the halide.

Supplementary Materials: The following are available online at https: / www.mdpi.com/article / 10.3390/cryst11121570/s1, Figure S1: Calculated and experimental PXRD; Figure S2: ${ }^{1} \mathrm{H}$ NMR in deuterated DMSO; Figure S3: TGA; Figure S4: PXRD of aged sample; Figure S5: Photoluminescence; Figure S6: Brillouin zone for P-1 space group; Figure S7: Density of states; Table S1: Summary of crystal data and structure refinement. 
Author Contributions: Conceptualization, N.M. and C.K.; methodology, M.K. and A.L.; investigation, M.B.H.S., J.T., X.C. and M.A.; writing, N.M., C.K. and M.K. All authors have read and agreed to the published version of the manuscript.

Funding: At ISCR and MOLTECH-Anjou the work was supported by the Agence Nationale pour la Re-cherche (MORELESS project). This work was granted access to the HPC resources of IDRIS under the allocation 2020-A0090907682 made by GENCI.

Institutional Review Board Statement: Not applicable.

Informed Consent Statement: Not applicable.

Data Availability Statement: The data for this study are available from the corresponding authors upon reasonable request.

Conflicts of Interest: The authors declare no conflict of interest.

\section{References}

1. Kumar Jena, A.; Kulkarni, A.; Miyasaka, T. Halide Perovskite Photovoltaics: Background, Status, and Future Prospects. Chem. Rev. 2019, 119, 3036-3103.

2. Gratzel, M. The Rise of Highly Efficient and Stable Perovskite Solar Cells. Acc. Chem. Res. 2017, 50, 487-491. [CrossRef]

3. Turren-Cruz, S.-H.; Hagfeldt, A.; Saliba, M. Methylammonium-Free, High-Performance and Stable Perovskite Solar Cells on a Planar Architecture. Science 2018, 362, 449-453. [CrossRef]

4. Correa-Baena, J.-P.; Saliba, M.; Buonassisi, T.; Grätzel, M.; Abate, A.; Tress, W.; Hagfeldt, A. Promises and challenges of perovskite solar cells. Science 2017, 358, 739-744. [CrossRef] [PubMed]

5. Aristidou, N.; Eames, C.; Islam, M.S.; Haque, S.A. Insights into the increased degradation rate of $\mathrm{CH}_{3} \mathrm{NH}_{3} \mathrm{PbI}_{3}$ solar cells in combined water and $\mathrm{O}_{2}$ environments. J. Mater. Chem. A 2017, 5, 25469-25475. [CrossRef]

6. Li, Z.; Yang, M.; Park, J.-S.; Wei, S.-H.; Berry, J.J.; Zhu, K. Stabilizing Perovskite Structures by Tuning Tolerance Factor: Formation of Formamidinium and Cesium Lead Iodide Solid-State Alloys. Chem. Mater. 2016, 28, 284-292. [CrossRef]

7. Saliba, M.; Matsui, T.; Domanski, K.; Seo, J.-Y.; Ummadisingu, A.; Zakeeruddin, S.M.; Correa-Baena, J.-P.; Tress, W.R.; Abate, A.; Hagfeldt, A.; et al. Incorporation of rubidium cations into perovskite solar cells improves photovoltaic performance. Science 2016, 354, 206-209. [CrossRef] [PubMed]

8. Saliba, M.; Matsui, T.; Seo, J.-Y.; Domanski, K.; Correa-Baena, J.-P.; Nazeeruddin, M.K.; Zakeeruddin, S.M.; Tress, W.; Abate, A.; Hagfeldt, A.; et al. Cesium-containing triple cation perovskite solar cells: Improved stability, reproducibility and high efficiency. Energy Environ. Sci. 2016, 9, 1989-1997. [CrossRef] [PubMed]

9. Shao, S.; Loi, M.A. Advances and Prospective in Metal Halide Ruddlesen-Popper Perovskite Solar Cells. Adv. Energy Mater. 2021, 11, 2003907. [CrossRef]

10. Mao, L.; Stoumpos, C.C.; Kanatzidis, M.G. Two-Dimensional Hybrid Halide Perovskites: Principles and Promises. J. Am. Chem. Soc. 2019, 141, 1171-1190. [CrossRef]

11. Zhang, F.; Lu, H.; Tong, J.; Berry, J.J.; Beard, M.C.; Zhu, K. Advances in Two-Dimensional Organic-Inorganic Hybrid Perovskites. Energy Environ. Sci. 2020, 13, 1154-1186. [CrossRef]

12. Saparov, B.; Mitzi, D.B. Organic-Inorganic Perovskites: Structural Versatility for Functional Materials Design. Chem. Rev. 2016, 116, 4558-4596. [CrossRef] [PubMed]

13. Katan, C.; Mercier, N.; Even, J. Quantum and Dielectric Confinement Effects in Lower-Dimensional Hybrid Perovskite Semiconductors. Chem. Rev. 2019, 119, 3140-3192. [CrossRef]

14. Tsai, H.; Nie, W.; Blancon, J.C.; Stoumpos, C.C.; Asadpour, R.; Harutyunyan, B.; Neukirch, A.J.; Verduzco, R.; Crochet, J.J.; Tretiak, S.; et al. High-efficiency two-dimensional Ruddlesden-Popper perovskite solar cells. Nature 2016, 536, 312-316. [CrossRef] [PubMed]

15. Leblanc, A.; Mercier, N.; Allain, M.; Dittmer, J.; Fernandez, V.; Pauporté, T. Lead and iodide deficient $\left(\mathrm{CH}_{3} \mathrm{NH}_{3}\right) \mathrm{PbI}_{3}, d-\mathrm{MAPI}$ The bridge between 2D and 3D hybrid perovskites. Angew. Chem. Int. Ed. 2017, 56, 16067-16072. [CrossRef] [PubMed]

16. Leblanc, A.; Mercier, N.; Allain, M.; Dittmer, J.; Pauporté, T.; Fernandez, V.; Boucher, F.; Kepenekian, M.; Katan, C. Enhanced Stability and Band Gap Tuning of $\alpha-\left[\mathrm{HC}\left(\mathrm{NH}_{2}\right)_{2}\right] \mathrm{PbI}_{3}$ Hybrid Perovskite by Large Cation Integration. ACS Appl. Mater. Interfaces 2019, 11, 20743-20751. [CrossRef] [PubMed]

17. Spanopoulos, I.; Ke, W.; Stoumpos, C.C.; Schueller, E.C.; Kontsevoi, O.Y.; Seshadri, R.; Kanatzidis, M.G. Unraveling the Chemical Nature of the 3D "Hollow" Hybrid Halide Perovskites. J. Am. Chem. Soc. 2018, 140, 17-5728. [CrossRef] [PubMed]

18. Ke, W.; Stoumpos, C.C.; Spanopoulos, I.; Chen, M.; Wasielewski, M.R.; Kanatzidis, M.G. Diammonium Cations in the FASnI 3 Perovskite Structure Lead to Lower Dark Currents and More Efficient Solar Cells. ACS Energy Lett. 2018, 3, 1470-1476. [CrossRef]

19. Hoffman, J.M.; Che, X.; Sidhik, S.; Li, X.; Hadar, I.; Blancon, J.F.; Yamaguchi, H.; Kepenekian, M.; Katan, C.; Even, J.; et al. From 2D to 1D Electronic Dimensionality in Halide Perovskites with Stepped and Flat Layers using Propylammonium as a Spacer. $J$ Am. Chem. Soc. 2019, 141, 10661-10676. [CrossRef] [PubMed] 
20. Kamminga, M.E.; Fang, H.-H.; Filip, M.R.; Giustino, F.; Baas, J.; Blake, G.R.; Loi, M.A.; Palstra, T.T.M. Confinement Effects in Low-Dimensional Lead Iodide Perovskite Hybrids. Chem. Mater. 2016, 28, 4554-4562. [CrossRef]

21. Mercier, N. Hybrid Halide Perovskites: Discussions on Terminology and Materials. Angew. Chem. Int. Ed. 2019, 58, 17912-17917. [CrossRef] [PubMed]

22. Stoumpos, C.C.; Mao, L.; Malliakas, C.D.; Kanatzidis, M.G. Structure-Band Gap Relationships in Hexagonal Polytypes and Low-Dimensional Structures of Hybrid Tin Iodide Perovskites. Inorg. Chem. 2017, 56, 56-73. [CrossRef] [PubMed]

23. Umeyama, D.; Leppert, L.; Connor, B.A.; Manumpil, M.A.; Neaton, J.B.; Karunadasa, H.I. Expanded Analogs of ThreeDimensional Lead-Halide Hybrid Perovskites. Angew. Chem. Int. Ed. 2020, 59, 19087-19094. [CrossRef] [PubMed]

24. Soler, J.M.; Artacho, E.; Gale, J.D.; García, A.; Junquera, J.; Ordejón, P.; Sánchez-Portal, D. The SIESTA method for ab initio order-N materials simulation. J. Phys. Condens. Matter 2002, 14, 2745-2779. [CrossRef]

25. Artacho, E.; Anglada, E.; Diéguez, O.; Gale, J.D.; García, A.; Junquera, J.; Martin, R.M.; Ordejón, P.; Pruneda, J.M.; Sánchez-Portal, D.; et al. The SIESTA method; developments and applicability. J. Phys. Condens. Matter 2008, 20, 064208. [CrossRef]

26. Dion, M.; Rydberg, H.; Schröder, E.; Langreth, D.C.; Lundqvist, B.I. Van der Waals Density Functional for General Geometries. Phys. Rev. Lett. 2004, 92, 246401. [CrossRef] [PubMed]

27. Cooper, V.R. Van der Waals density functional: An appropriate exchange functional. Phys. Rev. B Condens. Matter Mater. Phys. 2010, 81, 161104. [CrossRef]

28. Fernández-Seivane, L.; Oliveira, M.A.; Sanvito, S.; Ferrer, J. On-site approximation for spin-orbit coupling in linear combination of atomic orbitals density functional methods. J. Phys. Condens. Matter 2006, 18, 7999-8013. [CrossRef]

29. Zhang, Y.; Yang, W. Comment on “Generalized Gradient Approximation Made Simple". Phys. Rev. Lett. 1998, 80, 890. [CrossRef]

30. Troullier, N.; Martins, J.L. Efficient Pseudopotentials for Plane-Wave Calculations. Phys. Rev. B Condens. Matter Mater. Phys. 1991, 43, 1993-2006. [CrossRef]

31. Artacho, E.; Sánchez-Portal, D.; Ordejón, P.; García, A.; Soler, J.M. Linear-Scaling Ab-Initio Calculations for Large and Complex Systems. Phys. Stat. Sol. (b) 1999, 215, 809-817. [CrossRef]

32. Kamminga, M.E.; de Wijs, G.A.; Havenith, R.W.A.; Blake, G.R.; Palstra, T.T.M. The Role of Connectivity on Electronic Properties of Lead Iodide Perovskite-Derived Compounds. Inorg. Chem. 2017, 56, 8408-8414. [CrossRef] [PubMed]

33. Skorokhod, A.; Mercier, N.; Allain, M.; Manceau, M.; Katan, C.; Kepenekian, M. From 0D to 1D, opportunities and caveats of hybrid iodobismuthates for optoelectronic applications. Inorg. Chem. 2021, 60, 17123-17131. [CrossRef] [PubMed] 